\title{
SIGNIFICAÇÕES ATRIBUÍDAS POR PORTADORES DE VISÃO MONOCULAR À PERDA VISUAL E CIRURGIA DE CATARATA*
}

\author{
SIGNIFICATIONS IMPUTED BY MONOCULAR VISION CAREERS TO VISUAL LOSS AND CATARACT SURGERY
}

Roberta Ferrari Marbackํㅗㄹ Edméa R.Temporini², Otacílio O. Maia Júnior ${ }^{3}$, Newton Kara-Júnior ${ }^{4}$

${ }^{1}$ Psicóloga. Pós-graduanda (Nível Doutorado). ${ }^{2}$ Docente. Disciplina de Oftalmologia. ${ }^{3}$ Médico. Pós-graduando (Nível Doutorado). ${ }^{4}$ Médico. Chefe do Setor de Catarata. Faculdade de Medicina - USP. Hospital das Clínicas da FMUSP.

CoRRESPONDÊNCIA: Roberta Ferrari Marback (robertamarback@uol.com.br). Rua Eduardo José dos Santos, 147 - Centro Integrado de Saúde Prof. Fernando Filgueiras - sala 807/808 - Garibaldi. 41940-455 Salvador- BA.

Marback RF, Temporini ER, Maia Júnior OO, Kara-Júnior N. Significações atribuídas por portadores de visão monocular à perda visual e cirurgia de catarata. Medicina (Ribeirão Preto) 2007; 40 (4): 576-81, out./dez.

RESUMO: Objetivo: Identificar percepções e significados referentes à perda visual de pacientes que apresentavam visão monocular e diagnóstico de catarata, com indicação cirúrgica, por comprometimento visual significativo. Métodos: Desenvolveu-se estudo qualitativo, por meio de entrevistas abertas, com 8 sujeitos identificados por Campanha da Catarata, realizada no Hospital das Clínicas da Faculdade de Medicina da Universidade de São Paulo (HC-FMUSP), em novembro de 2004. Resultados: Dos entrevistados, 4 eram do sexo feminino e 4 do sexo masculino, tendo a idade variado de 38 a 86 anos. Referiram atividades profissionais como responsáveis pela perda visual, apontaram dificuldades para conseguir o atendimento médico, manifestaram desconhecimento e crenças populares em relação ao próprio problema ocular e dificuldades encontradas no cotidiano em decorrência da doença. Conclusões: Foram identificados significados, percepções, sentimentos, reações e experiências relacionados à catarata e à perda visual. A ocorrência da catarata no único olho significou angústia e situação conflituosa relacionadas à perda da independência. A expectativa de voltar a enxergar mediante intervenção cirúrgica prendeu-se ao sentimento de ter uma vida "normal", de sentir-se útil e do retorno ao mercado de trabalho.

Descritores: Visão Monocular. Catarata. Acuidade Visual. Percepção Visual. Pesquisa Qualitativa.

\section{1- INTRODUÇÃO}

A visão é um dos sentidos responsável por auxiliar o indivíduo na sua sobrevivência, em situações de defesa, segurança, alimentação, entre outras relacionadas à interação deste com o seu meio. ${ }^{1,2}$

A perda de um dos olhos para o indivíduo resulta em trauma psicológico e deformidade corporal. A transição para a visão monocular pode ser um pro- cesso difícil para o paciente, tanto funcional quanto psicologicamente, com repercussões sociais. Estudos apontaram que indivíduos referiram dificuldades em relação à aparência, mobilidade, dirigir automóvel, praticar esportes, desconforto e perda de status no emprego. A maioria relatou importância de treino formalizado, que julgava benéfico para adaptação, no sentido de auxiliá-los na estereopsia, nos aspectos psicológicos, na segurança e em atividades sociais. ${ }^{3}$

\footnotetext{
* Pesquisa realizada no Departamento de Oftalmologia do Hospital das Clínicas da Faculdade de Medicina - USP, com o apoio da "Coordenação de Aperfeiçoamento de Pessoal de Nível Superior (CAPES -MEC)", Brasília, Brasil
} 
Considera-se portador de visão monocular aquele que apresenta em um dos olhos acuidade visual menor ou igual a 0,1 , sem possibilidade de melhora. ${ }^{4}$

A catarata situa-se entre as principais causas de cegueira no mundo, porém é afecção ocular passível de recuperação mediante procedimento cirúrgico apropriado. No entanto, ressaltam-se dificuldades enfrentadas por portadores de catarata para submeterem-se à intervenção cirúrgica, devido à falta de acesso ao sistema de saúde, por limitações socioeconômicas e medo, falta de confiança e insegurança quanto aos resultados da cirurgia. ${ }^{5,6}$

No intuito de eliminar obstáculos e permitir ao paciente acesso com maior facilidade à consulta para detecção e tratamento da catarata, foram criados projetos comunitários. Desenvolvido desde 1987, o Projeto Catarata é realizado em dias de final de semana, em espaço geográfico acessível, com divulgação prévia de local e datas para o atendimento gratuito da comunidade. ${ }^{7,8} \mathrm{O}$ atendimento médico gratuito, no entanto, não significa tratamento para o paciente. Evidencia-se ser necessário considerar outros fatores, tais como crenças e hábitos..$^{5,7}$

A maneira pela qual cada pessoa reage a processos de enfermidade depende de sua personalidade, crenças, valores, ideologias, história de vida, apoio recebido e do tempo de doença. ${ }^{9}$

Nesse sentido, métodos qualitativos de pesquisa aplicados à área de saúde ocular propiciam entendimento do significado atribuído pelos indivíduos aos distúrbios da própria saúde. Esse significado influencia o cuidado com o qual organizam e assumem posturas de prevenção e tratamento de afecções passíveis de correção. ${ }^{10}$ Desse modo, o planejamento de possíveis intervenções educativas seria realizado com base em formas de pensar, sentir e agir da população, buscando sua adesão ao tratamento indicado..$^{10,11,12}$

O presente estudo teve por objetivo identificar percepções e significados referentes à perda visual de pacientes que apresentavam visão monocular e diagnóstico de catarata, com indicação cirúrgica, por comprometimento visual significativo. Ademais, teve-se o propósito de conhecer, da perspectiva dos sujeitos, fatores responsáveis por barreiras à prevenção/correção do distúrbio visual, que levaram ao retardamento da busca da assistência oftalmológica.

\section{2- MATERIAL E MÉTODOS}

Foi realizado estudo qualitativo, por meio de entrevistas abertas. Os sujeitos foram identificados por
Projeto Catarata realizada no Hospital das Clínicas da Faculdade de Medicina da Universidade de São Paulo (HC-FMUSP), em novembro de 2004. Dentre os pacientes que participaram do referido Projeto, 8 eram portadores de visão monocular, os quais fizeram parte do presente estudo - acuidade visual sem percepção luminosa (SPL) em um dos olhos e olho contralateral, visão menor ou igual a 0,3 (20/60). As entrevistas foram realizadas por um dos pesquisadores, individualmente, numa sala restrita. Esse método de pesquisa foi aplicado ao estudo de percepções e significados referentes à própria doença ocular, atribuídos por sujeitos que apresentavam visão monocular, com indicação cirúrgica para remoção da catarata. Esta pesquisa foi aprovada pela Comissão de Ética da instituição.

Antes de iniciar as entrevistas, foram explicados aos pacientes os objetivos e método da pesquisa, bem como assegurados sigilo e anonimato das informações por eles fornecidas, além da ausência de agravos ou prejuízos em relação ao tratamento oferecido na clínica oftalmológica. Os sujeitos assinaram termo de consentimento livre e esclarecido.

Realizaram-se entrevistas em profundidade e não-dirigidas, dialogando-se com o entrevistado de forma descontraída e com liberdade de expressão.

Procedeu-se à gravação da entrevista, após consentimento do sujeito. Os discursos foram transcritos na íntegra e seu conteúdo classificado em categorias, por meio do método de análise de conteúdo. Realizaram-se classificação e organização dos diversos aspectos mencionados pelos sujeitos, visando à descrição e interpretação dos significados conferidos ao objeto de estudo. ${ }^{10}$

\section{3- RESULTADOS}

Dos 8 pacientes entrevistados, 4 eram do sexo feminino e 4 , do sexo masculino, tendo a idade variado de 38 a 86 anos. Desses, 2 eram analfabetos, 4 cursaram as séries do ensino fundamental e 2, do ensino médio. Em relação à procedência, 5 eram do estado de São Paulo e 3 de estados do Nordeste. No que diz respeito ao nível socioeconômico, 6 referiram renda familiar de até um salário mínimo (SM), enquanto os outros 2, de dois a cinco SM. Todos os respondentes apresentaram em um dos olhos acuidade visual sem percepção luminosa (SPL); no olho contralateral, a acuidade visual foi menor ou igual 0,3 (20/60). Os resultados obtidos estão classificados e descritos a seguir, de acordo com os diferentes aspectos abordados pelos sujeitos. Distinguem-se os 
depoimentos utilizando-se aspas, parênteses e reticências, que indicam tratar-se do depoimento de cada entrevistado.

\section{1- Percepções referentes à perda visual e ati- vidades profissionais}

Ao serem solicitados a discorrerem acerca da perda da visão, alguns dos entrevistados relacionaramna às atividades profissionais. Nas palavras de alguns deles: “(...) Eu perdi, foi assim, trabalhando no posto de gasolina, então caiu sulupan, é que a gente espuluriza o carro por baixo para tirar a sujeira, ferrugem, depois fui trocar o óleo, caiu óleo quente na vista, mas já tava machucado de outras coisas, fui lavrador e chacoalhava café, veio um caroço e bateu nos olhos”; “(...) Eu estava trabalhando, aí caiu uma casquinha bem na menina do olho”; “(...) Eu perdi esse olho porque era empreiteiro, trabalhava demais da conta e esqueci que esse olho precisava ser operado".

\section{2- Vivências e perspectivas relacionadas à bus- ca da assistência oftalmológica}

Foram apontadas dificuldades para submeterse à consulta médica, em razão da demora em conseguir atendimento pelo Sistema Único de Saúde (SUS) e/ou pela falta de acesso às informações necessárias sobre como proceder diante de problema ocular. Ainda em relação a essa dificuldade, três dos entrevistados referiram ter perdido a visão desde criança, entretanto somente descobriram a causa e/ou perda depois de adultos. Assim, depreende-se de algumas falas: “(...) Como faz muito tempo que eu não tenho (a visão), desde criança que eu comecei a entender, eu já não tinha, só que não sabia o porque, descobri há pouco tempo, devido a toxoplasmose que deu primeiro no olho direito e, como não houve tratamento na época, eu perdi. Depois passou pro olho esquerdo, que é o que eu enxergo, fiz o tratamento, foi sanado e agora estou cuidando da catarata”; “(...) Olha, eu não posso te falar como perdi porque não sei, só descobri quando eu tinha 45 anos, que fui a primeira vez no oftalmo, aí que ela descobriu que eu tinha esse problema”.

O retardo na busca de atendimento médico pode ser percebido nas seguintes declarações: “(...) Aí passei um monte de dias sem ir no médico, quando fui, já estava com um mês”; “(...) Tanto serviço que tinha pra fazer que esqueci, ai quando passei pelo médico particular ele disse que tinha que operar depressa porque ia acabar de perder o restinho".

\subsection{Conseqüências da perda visual}

As limitações na mobilidade foram manifestadas de várias formas: “(...) Hoje em dia para mim sair só, não saio mais, porque não dá, a visão não dá, tenho que sair com uma pessoa, tenho que pedir para ler o letreiro do ônibus, não tomo ônibus sozinho".

A perda da função visual de um dos olhos foi mencionada por interferir bastante nas atividades diárias, impedindo sua execução; alguns referiram dificuldade de deambulação: “(...) Eu ia passar numa porta, esbarrava esse lado aqui, caminhava fazendo um triângulo, não caminhava reto, porque esse olho aqui é desligado desse. Ainda hoje me esbarro, mas é mais difícil. Era doído de passar nas portas e bater, muito ruim a gente perder um olho, além disso, quando a catarata começa a afetar o outro olho”; “(...) Ando pisando nos buracos, abraçando com os postes, sinto dor nas cadeiras de cair nos buracos e ando com acompanhante".

\section{4- Atribuições de causa à perda visual}

Alguns entrevistados referiram crenças populares em relação à perda da função visual: “(...) Aí eu fui para minha terra, levei meio dia viajando, a quentura muito grande, aí quando eu cheguei lá a dor bateu em cima e ele vazou, não teve mais jeito.”; “(...) Eu tinha uma cicatriz que não sabia de onde veio, se é de nascença ou se foi quando era bebê, de um bicho de verdura, que pode ser que comeu os olhos".

\section{5- Sentimentos e experiências relacionados à perda visual}

Ao se referirem à perda da visão, a maioria dos entrevistados relatou tristeza, constrangimento, "tendo que enfrentar a dura realidade" e passar por diversas dificuldades no cotidiano. Na expressão de alguns entrevistados: “(...) Еu me sinto assim péssima porque não enxergo de um e o outro que enxergo está com complicação, não consigo ler um livro, ler um nome de um ônibus, dirigir, fazer praticamente nada. Coisa rotineira, simples, do dia-a-dia, de olhar uma pessoa do outro lado da rua e não saber quem é, porque não estou vendo o rosto dela. É como não ter um dedo, um braço, é horrível"; “(...) Eu senti no buraco do poço, sem saída. Ficar numa situação que eu não posso levar um pão pra casa, um arroz, um feijão, um açúcar, o que precisar, pagar aluguel, luz e água, o que a gente 
serve é criado pela mão dos outros e é isso que eu estou com medo, estou correndo aqui pra ver se opero e voltar a fazer qualquer coisa, entrar uns trocadinhos em casa".

Apenas um dos pacientes, o qual referiu ter nascido sem a capacidade visual em um dos olhos, relatou não perceber diferença diante da perda da visão: “(...) Eu não sinto diferença nenhuma, me sinto perfeito, como outro que tem dois, entendeu? A única dificuldade é essa agora, fica tudo embaçado para ver o ônibus".

\section{6- Reações à doença ocular}

Na presença da enfermidade, os sujeitos mencionaram alguma forma para enfrentá-la. Como revelou um entrevistado: “(...) Se a gente ficar pensando demais é pior, é melhor deixar o tempo levar. Às vezes eu saio, não fico só pensando naquilo ali, vou andar".

Dois sujeitos mostraram-se receosos diante da cirurgia, mas não descartaram a possibilidade cirúrgica e de obtenção de sucesso: “(...) Eu fico com medo dele vazar como o outro, mas na mesma hora eu confio em Deus, Ele não vai fazer eu ficar cega (...)”, “(...) Deus vai me proteger, me dar força, coragem, pra eu resistir à operação, Ele vai fazer tudo para que eu fique com minha vista boa. Eu espero que fique boa, estou com vontade de viajar para minha terra, para o Maranhão”; “(...) Às vezes a pessoa fica meio na dúvida, agora se há necessidade, a gente não tem outro recurso, tem que fazer".

\section{7- Percepções e expectativas em relação à ci- rurgia de catarata}

A esse respeito registram-se algumas falas: “(...) Olha, a única coisa que eu sei é que parece que coloca uma lente, do resto eu não sei mais nada"; “(...) Do graucoma eu sei, porque eu sofri muito para operar, as injeção que deram dentro do olho, agora a catarata, eu não sei, penso que é uma raspagem”; “(...) A gente fica preocupada, quando eu fiz a primeira, eu já fiquei preocupada, na segunda, fiz um marcapasso, eu passei muito mal, fiquei 11 dias na UTI, então, toda cirurgia é difícil, mas eu acho que da vista é o pior que tem, porque você não pode perder a vista, então a gente fica preocupada".
No que diz respeito ao período pós-cirúrgico, os sujeitos referiram: “(...)Eu imagino, espero $e$ preciso, estou sem trabalhar, preciso voltar ao mercado de trabalho, quero voltar a estudar, quero fazer Direito e só com um olho eu vou poder voltar a fazer, desde uma coisa simples, rotineira, até a volta aos estudos. Ah, se a cirurgia der certo e eu conseguir fazer tudo isso, para mim vai mudar tudo. Acho que vou me sentir uma outra pessoa, me sentir mais gente”; “(...) Se eu conseguir operar e melhorar, eu penso em arranjar alguma coisa para fazer. Para melhorar a situação mais um pouco”; “(...) Voltar a enxergar, tudo bem que é de uma visão só, mas voltar a enxergar normalmente já é uma, é como ganhar um braço novo, eu acho, imagino assim, quem não tem um braço, ganhar uma prótese, quem não tem uma orelha, ganhar uma cirurgia plástica e quem está com a visão prejudicada, ganhar uma nova visão, isso é maravilhoso, não importa como seja, se tem que ficar numa fila dessa ou não. O que importa pra mim é chegar ao final: eu voltar a enxergar para poder voltar a fazer minhas coisas".

\section{4- DISCUSSÃO}

Os dados obtidos nas entrevistas indicam que os sujeitos tendem a atribuir à atividade profissional alguma influência na perda da visão; consideram atividades laborais responsáveis por essa perda e pela busca tardia do tratamento oftalmológico, não importando a ocupação por eles exercida. Esse fato revelase na menção feita por um dos sujeitos, atribuindo a perda visual à ação química de substância que atingiu o globo ocular. Resultados semelhantes foram obtidos por meio de "survey", realizado no ano de 2005 num hospital universitário, com 110 sujeitos com diagnóstico e indicação cirúrgica de catarata. Esse estudo evidenciou que os respondentes atribuíram a catarata ao cansaço visual devido a atividades profissionais $(37,0 \%)$, exposição ao calor $(12,5 \%)$ e a produto quí$\operatorname{mico}(18,6 \%){ }^{13}$

A busca do atendimento oftalmológico de população de baixa renda, em geral, centra-se em serviços públicos de saúde. A amostra do presente estudo originou-se da realização de Projeto Catarata, como forma de viabilizar o acesso dessa população ao tratamento cirúrgico da catarata.

Foi percebido retardo na busca de assistência oftalmológica, seja pela falta de informação ou pela 
dificuldade em conseguir consulta pelo SUS; por conta disso, quando o paciente comparecia ao atendimento, a doença já se encontrava num estado tão avançado que não tinha opção de tratamento, resultando na perda da função visual. Assim, nota-se que falta de conhecimentos adequados parece influir no descuido em relação ao problema ocular, resultando na cegueira.

Destaca-se que a importância que cada indivíduo atribui a sua saúde está vinculada aos padrões socioeconômicos, conhecimentos, hábitos, atitudes e crenças, de acordo com o meio no qual este se encontra inserido. ${ }^{14}$ Tais padrões podem influir na decisão sobre busca do atendimento médico.

A dificuldade percebida em relação às práticas cotidianas mostrou-se bastante presente. Observou-se que o problema que já existia com a perda da função visual de um dos olhos foi acentuado com o surgimento da catarata que, para o paciente, é algo muito difícil. $\mathrm{O}$ que antes era percebido como limitação, passa a não mais poder ser executado, fato que os entrevistados apontaram, revelando um certo sofrimento, já que passavam a ter que depender do outro para exercer atividades, desde as básicas do cotidiano, até outras mais complexas.

Concepções populares relacionadas à saúde/doença decorrem da aprendizagem informal que se origina no meio familiar, na história de vida, na convivência com as pessoas, na mídia e através da cultura. Revestem-se de certeza e influenciam o comportamento individual e social, podendo se constituir em fatores determinantes de ações indesejáveis para a detecção e tratamento de doenças oculares. ${ }^{15}$

Ressalte-se que descrença e falta de conhecimentos em relação à causa e tratamento da catarata indicam necessidade de intervenções educativas de promoção da saúde ocular. ${ }^{8,16}$

$\mathrm{O}$ fato mencionado pelos respondentes em relação à maior facilidade de aceitação da condição de perda visual quando esta ocorre na infância, já que as chances de reintegrar-se totalmente à vida é bem maior do que aquela que deva ser assumida repentinamente em razão de um problema, ao qual terá que se adaptar foi também evidenciado por Botelho et al. ${ }^{1}$. Assim, o desenvolvimento da criança acontece de acordo com seu convívio precoce com limitações. Esses autores chamaram a atenção para o fato de que entrar em contato com uma limitação até en- tão ausente na vida é tornar-se frágil, pois diz respeito a questões internas, que serão enfrentadas de acordo com experiências prévias e subjetividade de cada indivíduo.

Apesar de alguns dos discursos revelarem desconhecimentos e receio em realizar a cirurgia, evidenciou-se a existência de fé, relacionada à religiosidade, indicando pretensão de submeter-se ao procedimento, no intuito de conseguir enxergar, como antes do surgimento da catarata, e poder voltar a exercer atividades cotidianas.

Estudo acerca das concepções populares do tratamento da catarata senil ressaltou a influência do sentimento de religiosidade, atribuindo à vontade de Deus a ocorrência da perda visual; esse modo de pensar pode conduzir ao conformismo, gerando entraves à busca de tratamento reparador. ${ }^{8}$

Notou-se ausência de conhecimentos prévios e manifestação de receios e dúvidas em relação à cirurgia de catarata.

Observou-se que planos futuros estavam bastante presentes nos discursos dos pacientes, que relataram esperar resultado favorável da intervenção cirúrgica, com intenção de voltar a enxergar como antes, voltar a ter uma vida "normal", ter uma rotina como qualquer outra pessoa, sentir-se útil e voltar ao mercado de trabalho.

A literatura aponta resultados cirúrgicos bastante satisfatórios da extração da catarata, decorrentes dos avanços tecnológicos e crescente número de cirurgiões habilitados para tal procedimento, aplicando técnicas seguras e eficazes. ${ }^{17}$ Portanto, pacientes com olho único e indicação cirúrgica de catarata, situação conflituosa e angustiante, devem ser encorajados para a realização da cirurgia, com possibilidade de reabilitação visual significativa.

\section{5- CONCLUSÕES}

O estudo qualitativo possibilitou identificar significados, percepções, sentimentos, reações e experiências relacionadas à catarata e à perda visual. A ocorrência da catarata no único olho significou angústia e situação conflituosa relacionadas à perda da independência. A expectativa de voltar a enxergar mediante intervenção cirúrgica prendeu-se ao sentimento de ter uma vida "normal", de sentir-se útil e do retorno ao mercado de trabalho. 
Marback RF, Temporini ER, Maia Júnior OO, Kara-Júnior N. Significations imputed by monocular vision careers to visual loss and cataract surgery. Medicina (Ribeirão Preto) 2007; 40 (4): 576-81, oct./dec.

ABSTRACT: Purpose: To identify perceptions and significations relating to the visual loss and the cataract surgery among monocular vision patients who present surgical indication by means of a impairment. Methods: A qualitative study through open interviews with 8 individuals identified by the Cataract Project, was conducted in Hospital das Clínicas, São Paulo University Medical School (HC-FMUSP), during November, 2004. Results: The study included 4 women and 4 men, ages from 38 to 86 years old. They reported professional activities as liable for the visual loss, pointed out difficulties to get medical care and revealed popular beliefs and insufficient knowledge about their own ocular problem. Conclusions: Meanings, perceptions, feelings, reactions and experiences were identified related to cataract and visual loss, in general attributed to their professional activity. The occurence of cataract in a single eye signified to them anguish and conflictive situation related to loss of independence. Expectancy of seeing again through surgical procedure became attached to the sense of having a normal and useful life and by the fact of returning to the labour market.

Keywords: Vision, Monocular. Cataract. Visual Acuity. Visual Perception. Qualitative Research.

\section{6- REFERÊNCIAS}

1 - Botelho NLP, Volpini M, Moura EM. Aspectos psicológicos em usuários de prótese ocular. Arq Bras Oftalmol 2003; 66 (5): 637-46.

2 - Cyrillo PI. Aspectos psicológicos relacionados aos portadores de lesões oculares e a utilização de próteses. In: Fonseca EPD. Prótese ocular. São Paulo: CIP; 1987. p. 181- 7.

3 - Coday MP, Warner MA, Jahrling KV, Rubin PAD. Acquired monocular vision: functional consequences from the patient's perspective. Ophthal Plast Reconstr Surg 2002; 18(1):56-63.

4 - Centurion V, Carrari MJB, Caballero JC, Lacava AC. Cirurgia da catarata em portadores de olho único. Rev Bras Oftalmol 2000; 59(8):572-6.

5 - Kara-José Jr N, Schellini AS, Silva MRBM, Bruni LF, Almeida AGC. Projeto catarata - qual a sua importância para a comunidade? Arq Bras Oftalmol 1996; 59(6):490-6.

6 - Temporini ER, Kara-José N, Kara-José Jr N. Catarata senil: características e percepções de pacientes atendidos em projeto comunitário de reabilitação visual. Arq Bras Oftalmol 1997; 60(1):79-83

7 - Kara-José N, Temporini ER. Cirurgia de catarata: o porquê dos excluídos. Rev Panam Salud Publica. 1999; 6(4):242-8.

8 - Temporini ER, Kara-José N, Kara-José Jr N, Holzchuh N. Popular beliefs regarding the treatment of senile cataract. Rev Saúde Pública 2002; 36(3):343-9.

9 - Botega NJ. Reação à doença e à hospitalização. In: Botega NJ (org.). Prática psiquiátrica no hospital geral: interconsulta e emergência. Porto Alegre: Artmed Editora, 2002. p. 43-59.
10 - Turato ER. Métodos qualitativos e quantitativos na área da saúde: definições, diferenças e seus objetos de pesquisa. Rev Saúde Pública, 2005; 39 (3):507-14.

11 - Briceño-León R. Siete tesis sobre la educación sanitaria para la participación comunitária. Cad Saúde Públ 1996; 12:7-30.

12 - Minayo MCS. O desafio do conhecimento: pesquisa qualitativa em saúde. São Paulo: Hucitec/Rio de Janeiro: Abrasco, 2004.

13 - Marback RF, Temporini ER, Maia Jr OO, Schaefer T, KaraJosé Jr N, Kara-José N. Atividade ocupacional e catarata senil - opinião de pacientes de hospital universitário. Medicina (Ribeirão Preto) 2005; 38:301-9.

14 - Temporini ER Ação preventiva em problemas visuais de escolares. Rev Saúde Pública 1984; 18:259-62.

15 - Rocha JCP, Gondim EL, Braga FTC Dantas FJ, Temporini ER, Kara-José N. Ocular health myths among a hospital staff. Ophthalmic Epidemiol 1997; 4(2):107-13.

16 - Kara Jr N, Temporini ER, Kara José N. Cataract surgery: expectations of patients assisted during a community project in São Paulo, state of São Paulo, Brazil. Rev Hosp Clin Fac Med S Paulo, 2001; 56(6):163-8.

17 - Avakian A, Temporini ER, Kara José N. Second eye cataract surgery: perceptions of a population assisted at a university hospital. Clinics 2005; 60(5):401-6.

Recebido em 23/05/2007

Aprovado em 16/08/2007 